\title{
QUANTIFYING NEARSHORE MORPHOLOGICAL RECOVERY TIME SCALES USING ARGUS VIDEO IMAGING: PALM BEACH, SYDNEY AND DUCK, NORTH CAROLINA
}

\author{
Roshanka Ranasinghe ${ }^{1,2,3}$, Rob Holman ${ }^{4}$, Matthieu de Schipper ${ }^{2}$, Tom Lippmann ${ }^{5}$, Jennifer \\ Wehof $^{6}$, Trang Minh Duong ${ }^{1,3}$, Dano Roelvink ${ }^{1}$, and Marcel Stive ${ }^{2}$
}

\begin{abstract}
Time scales of post-storm nearshore morphological recovery and physical processes governing these time scales are poorly understood at present. The ability to predict nearshore morphological recovery time scales based on pre-, during- or post-resetting storm conditions is an essential requirement for building and validating scale aggregated models that operate at macro- and higher spatio-temporal scales. In this study, quality controlled ARGUS video derived beach states at Palm Beach, Sydney (4 years) and Duck, NC (2 years) and concurrent wave data are analysed to quantify the nearshore morphological recovery time scales $\left(T_{m r}\right)$ and to determine the physical processes that may govern $T_{m r}$. The results show that $T_{m r}$ is of the order of 5-10 days at these two beaches. $T_{m r}$ is moderately positively correlated with the averaged longshore current over the 3 days immediately after the resetting storm, indicating that it might be possible to develop a predictor for $T_{m r}$ based on wave conditions immediately after the resetting storm. Weak correlations are present between $T_{m r}$ and several pre-storm, during-storm and post-storm parameters at the two sites. However, these correlations are inconsistent between the two sites. A thorough analysis employing long-term beach state and wave data at several different study sites is required to fully understand this phenomenon.
\end{abstract}

Keywords: Morphological resets, Storm impact, recovery time scales, ARGUS

\section{INTRODUCTION}

How long does it take for nearshore morphology to recover after a storm induced morphological reset event? Is the morphological recovery time scale $\left(T_{m r}\right)$ more or less the same at beaches with similar characteristics, or is it completely random? Are there any physical processes that govern $T_{m r}$, or is it governed by scale-aggregated self-organising behavioural characteristics? These are important questions that need to be answered to further our understanding of macro-scale coastal behaviour, which is a prerequisite to build and validate predictive models at macro- and higher spatio-temporal scales. From an applied point of view, even a qualitative knowledge of $T_{m r}$ will aid amphibious operations. Furthermore, coastal management/planning decision support tools that account for long term (decadal to centennial) coastline behaviour (e.g. Callaghan et al., 2008; Ranasinghe et al., 2012) will greatly benefit from a knowledge of $T_{m r}$ because it is unlikely that dune recovery will occur before the nearshore morphology recovers after storm induced resets (i.e. initiation of dune recovery will almost always occur after $T_{m r}$ has been reached).

Over the last three decades, a considerable amount of research effort has gone into understanding the morphodynamic processes governing the upstate/downstate transitions between beach states (as defined by Wright and Short, 1984), using field observations (Wright et al., 1985; Brander 1999), ARGUS video imaging (Lippmann and Holman, 1990; Ranasinghe et al., 2004, Turner et al 2007; Ojeda et al., 2011; Price and Ruessink, 2011), and numerical modelling (Damgaard et al., 2002; Reniers et al., 2004; Drønen and Deigaard, 2007; Calvete et al., 2007; Smit et al., 2008; Castelle et al., 2012). However, to date, there has been no concerted research effort focussing specifically on the important issue of nearshore morphological recovery time scales. The present study takes an initial step towards addressing this knowledge gap.

\footnotetext{
${ }^{1}$ UNESCO-IHE Institute for Water Education, Delft, The Netherlands.

${ }^{2}$ Coastal Engineering, Section of Hydraulic engineering, Delft University of Technology, Delft, The Netherlands.

${ }^{3}$ Harbour, Coastal and Offshore Engineering, Deltares, PO Box 177, $2600 \mathrm{MH}$ Delft, The Netherlands

${ }^{4}$ Oceanography Department. Oregon State University, Corvallis, Oregon, USA.

${ }^{5}$ Center for Coastal \& Ocean Mapping, University of New Hampshire, Durham, New Hampshire, USA

${ }^{6}$ Environmental Engineering, Stevens Institute of Technology, Hoboken, New Jersey, USA.
} 


\section{METHODS}

Here we define $T_{m r}$ as the time (days) it takes for the nearshore morphology to evolve from a poststorm Dissipative or Longshore Bar Trough state (D/LBT) to its modal state (i.e. the most frequently occurring beach state), be it Rhythmic Bar Beach (RBB), Transverse Bar Rip (TBR), Low Tide Terrace (LTT), or Reflective (R). The critical requirement for the quantification of $T_{m r}$ is the availability of a beach state and wave characteristics data set that is of high quality, sufficient length (multi-year) and sufficient temporal resolution (daily). The ARGUS video data presented by Lippmann and Holman (1990) (2 Years of daily data at Duck, NC- Oct 1986 to Oct 1988) and Ranasinghe et al. (2004) (4 years of daily data at Palm Beach, Sydney - Jan 1996 to Dec 1999) satisfy these requirements (Figures 1 and 2). These two data sets are the only ARGUS beach state data sets that have been rigorously quality controlled. Random samples from both data sets were subjected to independent visual beach state classifications by a panel of coastal experts/non-experts and the levels of consensus were quantified. In both cases, the overall agreement between the classification panels and the authors exceeded $75 \%$ (i.e. over $75 \%$ of the states classified by the authors were classified as the same state by the panel members). Therefore, a high level of confidence can be placed on these two data sets.

Both sites are located in microtidal environments. The annual average significant wave periods are similar at the two sites, while annual average wave height is about 50\% higher at Palm beach (i.e. $1.6 \mathrm{~m}$ vs $1.0 \mathrm{~m}$ ). The average storm wave heights and periods for Palm Beach and Duck are $2.9 \mathrm{~m}, 9 \mathrm{~s}$ and $1.6 \mathrm{~m}$, 8s. The foreshore grain size $\left(D_{50}\right)$ is $0.3 \mathrm{~mm}$ at Palm Beach while it is about $1 \mathrm{~mm}$ at Duck. Palm beach is single barred, while Duck fluctuates between a single (25\% of the time) and double barred beach. For consistency, Lippmann and Holman's (1990) beach state classifications of the inner bar at Duck which followed their 8 state scheme, were re-classified into Wright and Short's (1984) 6-state model.
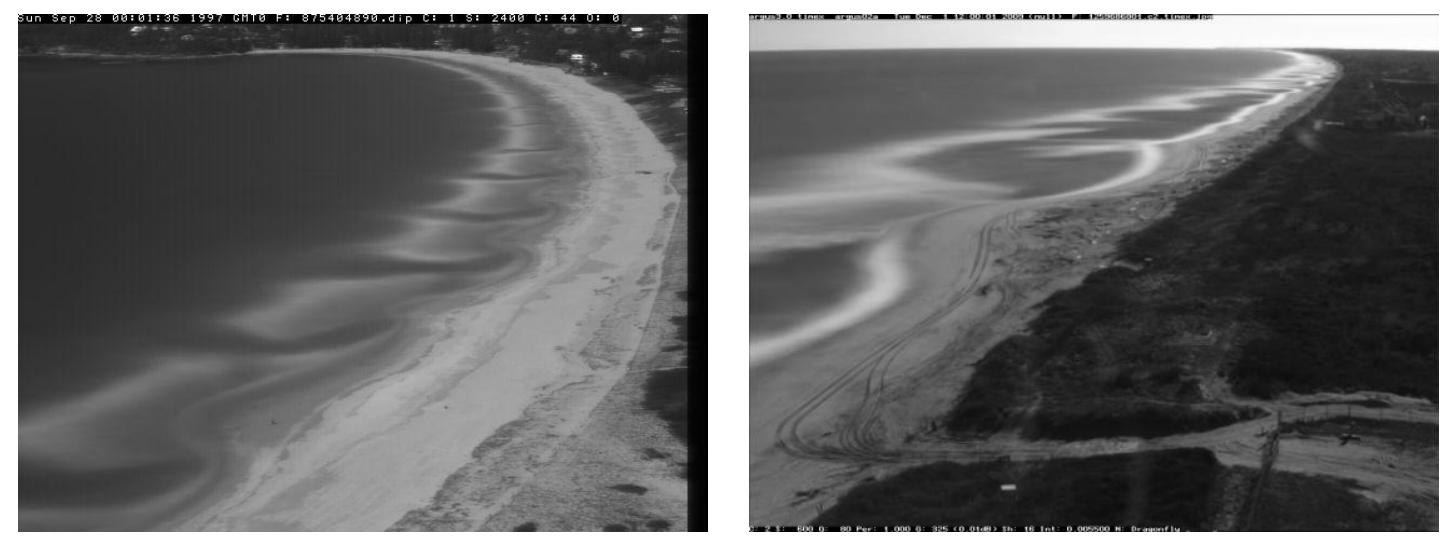

Figure 1. Time averaged Argus video images of Palm Beach, Sydney (left) and Duck, North Carolina (right). 


\section{RESULTS}

Beach state time series for both beaches are shown in Fig. 2. A reset event is indicated by a beach state transition to D/LBT (or State 4) from any other state. The modal beach state at both sites is the TBR state (55\% and 36\% at Palm beach and Duck respectively).
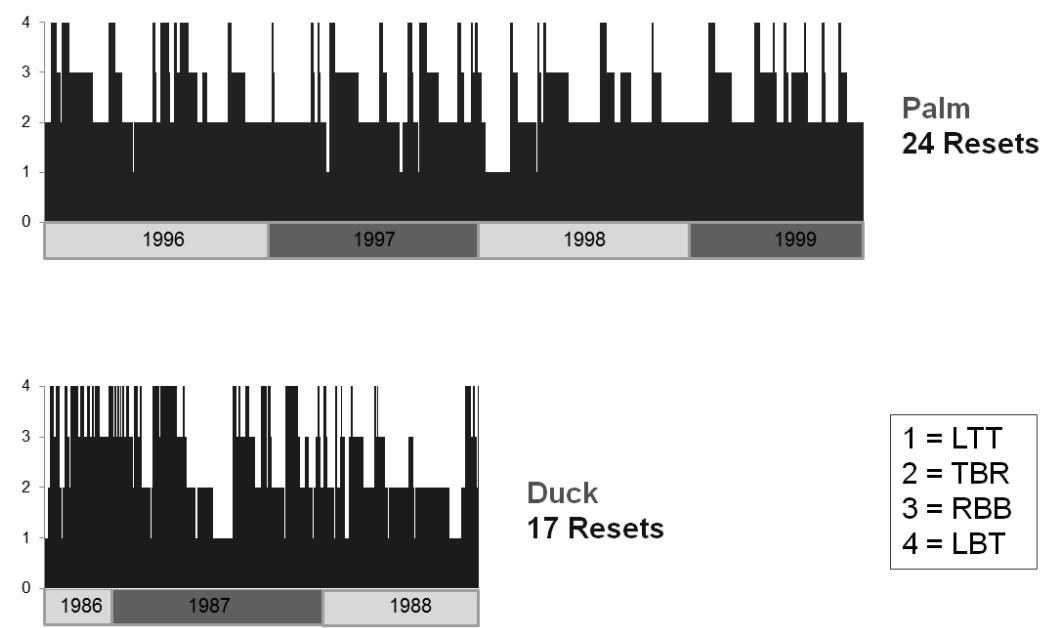

Figure 2. Beach state time series for Palm Beach, AUS (top) and Duck, NC (bottom).

Summary statistics of the morphological recovery durations determined at the two sites, using the definition for $T_{m r}$ given above, are shown in Table 1. The high standard deviations and the low count numbers associated with the mean and modal values indicate that these statistics may not be of any significance in these two data sets. Therefore, the median value appears to be the best statistical indicator of $T_{m r}$. Interestingly, $T_{m r}$ at Palm Beach is about double that of Duck. It is also noteworthy that previous numerical modelling efforts which mimicked Palm beach conditions predicted recovery durations that are 50\% lower (Reniers et al., 2004) or 50\% higher (Damgaard et al., 2002) than the observed $T_{m r}$ of 11 days at Palm beach.

\begin{tabular}{|l|c|c|c|c|c|}
\hline \multicolumn{6}{|c|}{ Table 1. Summary statistics of morphological recovery duration ( $\mathbf{T}_{\mathrm{mr}}$ ) at Palm beach, and Duck. } \\
\hline & $\begin{array}{c}\text { Total recovery } \\
\text { events }\end{array}$ & $\begin{array}{c}\text { Mean } T_{\mathrm{mr}} \\
\text { (days) }\end{array}$ & $\begin{array}{c}\text { Std. deviation } \\
\text { (days) }\end{array}$ & $\begin{array}{c}\text { Modal } T_{m r} \\
\text { (days) }\end{array}$ & $\begin{array}{c}\text { Median } T_{m r} \\
\text { (days) }\end{array}$ \\
\hline Palm beach & 24 & 17 & 14 & $\begin{array}{c}6 \\
\text { [7 occurrences] }\end{array}$ & 11 \\
\hline Duck & 17 & 7 & 5 & $\begin{array}{c}5 \\
\text { [6 occurrences] }\end{array}$ & 5 \\
\hline
\end{tabular}

The significant differences between the $T_{m r}$ values observed at the two sites raises the 'why' question. To seek answers, a series of cross-correlations between $T_{m r}$ and wave/morphological characteristics were undertaken. Cross correlations performed included those between $T_{m r}$ and maximum wave height and wave power during the storm, between $T_{m r}$ and averaged wave height, period, direction, wave steepness, wave breaking intensity and longshore current 3-7 days immediately after the storm, 3-7 days immediately prior to recovering to the modal state, and during the entire recovery duration. Wave breaking intensity was estimated by the Iribarren number (Battjes, 1974) and longshore current was approximated by $H^{2} \cos \theta$. Correlations were also performed between $T_{m r}$ and the antecedent (to the reset event) beach state. The results are given below in Tables 2-9. Correlations that are statistically significant at $95 \%$ are shown in bold font in all tables, and are the only correlations that are discussed below. All wave heights are significant wave heights, periods are peak periods, and directions are relative to the shore normal.

\section{Conditions just before and during resetting storm}

Table 2 indicates that there is a weak positive correlation (bold) between antecedent beach state and $T_{m r}$ at Duck such that $T_{m r}$ increases when antecedent beach state is in a higher state. Correlations between $T_{m r}$ and resetting storm conditions are given in Table 3 and indicate weak positive correlations 
between storm power and $T_{m r}$ at Palm beach and between maximum offshore storm wave height and $T_{m r}$ at Duck.

\begin{tabular}{|c|c|c|}
\hline & Beach State & Bar position \\
\hline Palm beach & -0.11 & 0.1 \\
\hline Duck & 0.43 & -0.25 \\
\hline
\end{tabular}

\begin{tabular}{|c|c|c|}
\hline & $\begin{array}{c}\text { Max wave height } H_{s} \\
\text { offshore }\end{array}$ & Storm Power \\
\hline Palm beach & 0.07 & 0.47 \\
\hline Duck & 0.43 & 0.38 \\
\hline
\end{tabular}

\section{Conditions immediately after the resetting storm}

Tables 4 and 5 show correlations between various wave parameters immediately after the storm (averaged over 3, 5 and 7 days after the resetting storm subsided) and $T_{m r}$ at Palm beach and Duck, respectively. Wave height observations offshore overestimate the inshore waveheights for highly oblique waves due to refraction. Therefore waveheights are also translated to an estimated waveheight $H_{b}$ at the surfzone egde. The inshore waveheight estimation was calculated by using the linear dispersion relation and including refraction and shoaling effects on the wave height. Note that wave direction was not available at Duck for this analysis and hence parameters that require wave angle to obtain an inshore wave height estimate (i.e. $H_{b}, H_{b} / L$, Iribarren ${ }_{\mathrm{b}}$ ) and longshore current could not be estimated for Duck. Table 4 indicates a moderate (italic bold) positive correlation between $T_{m r}$ and the 3-day averaged longshore current. Weak positive correlations are indicated between the 5-day averaged longshore current, and the 3,5 and 7-day averaged offshore wave heights $\left(H_{o}\right)$ and $T_{m r}$ and a weak negative correlation is indicated between $T_{m r}$ and the 3-day averaged offshore Iribarren number. At Duck, the only statistically significant (at 95\%) correlation that can be seen is the weak positive correlation between $T_{m r}$ and the 3-day averaged offshore Iribarren number (Table 5).

\begin{tabular}{l} 
Table 4. Correlation coefficients $T_{\boldsymbol{m r}}$ and wave conditions immediately after the storm for Palm Beach, Aus. Bold \\
values indicate 95\% significance. \\
\hline Average over
\end{tabular}

\begin{tabular}{|c|c|c|c|c|}
\hline Average over & $H_{0}$ & $T_{p}$ & $H_{0} / L$ & $\begin{array}{c}\text { Iribarren } \\
\text { w. wave height } H_{0}\end{array}$ \\
\hline 3 days & -0.20 & 0.38 & -0.37 & 0.42 \\
\hline 5 days & -0.20 & 0.02 & 0.09 & 0.15 \\
\hline 7 days & -0.23 & 0.01 & 0.04 & 0.06 \\
\hline
\end{tabular}

\section{Conditions during the entire recovery duration}

Tables 6 and 7 show correlations between various wave parameters during the entire recovery duration and $T_{m r}$ at Palm beach and Duck, respectively. Table 6 indicates weak positive correlations 
between $T_{m r}$ and averaged $H_{o}, H_{d} / L, H_{b} / L$, and longshore current and a weak negative correlation with averaged Iribarren $_{\mathrm{b}}$ at Palm beach. Table 7 indicates a weak negative correlation between $T_{m r}$ and averaged $H_{o}$ at Duck.

\begin{tabular}{|c|c|c|c|c|c|c|c|c|}
\hline$H_{0}$ & $T_{p}$ & $\theta$ & $H_{b}$ & $H_{d} / L$ & $H_{b} / L$ & $\begin{array}{l}\text { Iribarren } \\
\text { w. wave } \\
\text { height } H_{0}\end{array}$ & $\begin{array}{l}\text { Iribarren } \\
\text { w. wave } \\
\text { height } H_{b}\end{array}$ & $\begin{array}{c}\text { Longshore } \\
\text { current } \\
\text { magnitude } \\
\left(\mathrm{H}^{2} \cos (\theta)\right)\end{array}$ \\
\hline 0.46 & 0.11 & 0.03 & 0.35 & 0.57 & 0.56 & -0.39 & -0.42 & 0.41 \\
\hline
\end{tabular}

\begin{tabular}{|c|c|c|c|}
\hline$H_{0}$ & $T_{p}$ & $H_{0} / L$ & $\begin{array}{c}\text { Iribarren } \\
\text { w. wave height } H_{0}\end{array}$ \\
\hline-0.48 & 0.13 & -0.13 & 0.27 \\
\hline
\end{tabular}

\section{Conditions immediately prior to recovery}

Tables 8 and 9 show correlations between various wave parameters immediately prior to recovery (3, 5 and 7 days prior to reaching modal beach state) and $T_{m r}$ at Palm beach and Duck, respectively. At Palm beach (Table 8), moderate positive correlations are indicated between $T_{m r}$ and 7-day averaged $H_{o}$, $H_{b}$ and longshore current. Weak positive correlations are indicated between $T_{m r}$ and 7-day averaged $H_{d} / L$ and $H_{b} / L$ and a weak negative correlation is indicated with 7-day averaged Iribarren ${ }_{b}$. At Duck (Table 9), a moderate negative correlation between $T_{m r}$ and the 7-day averaged $H_{o}$ is indicated. $T_{m r}$ is also weakly positively correlated with the 3-day averaged Iribarren and weakly negatively correlated with the 5 day averaged $H_{o}$ and the 7 day averaged $T_{p}$.

\begin{tabular}{|c|c|c|c|c|c|c|c|c|c|}
\hline $\begin{array}{c}\text { Average } \\
\text { before } \\
\text { reaching } \\
\text { modal state } \\
\text { over }\end{array}$ & $H_{0}$ & $T_{p}$ & $\theta$ & $H_{b}$ & $H_{o} / L$ & $H_{b} / L$ & $\begin{array}{l}\text { Iribarren } \\
\text { w. wave } \\
\text { height } H_{0}\end{array}$ & $\begin{array}{l}\text { Iribarren } \\
\text { w. wave } \\
\text { height } H_{b}\end{array}$ & $\begin{array}{c}\text { Longshore } \\
\text { current } \\
\text { magnitude } \\
\left(\mathrm{H}^{2} \cos (\theta)\right)\end{array}$ \\
\hline 3 days & -0.29 & -0.14 & -0.16 & -0.15 & -0.23 & -0.01 & 0.27 & 0.06 & -0.37 \\
\hline 5 days & -0.30 & -0.15 & -0.11 & -0.09 & -0.04 & -0.09 & 0.11 & 0.17 & -0.25 \\
\hline 7 days & 0.61 & 0.27 & -0.19 & 0.75 & 0.48 & 0.44 & -0.08 & -0.50 & 0.61 \\
\hline
\end{tabular}

\begin{tabular}{|c|c|c|c|c|}
\hline $\begin{array}{c}\text { Average before } \\
\text { reaching modal state } \\
\text { over }\end{array}$ & $H_{0}$ & $T_{p}$ & $H_{0} / L$ & $\begin{array}{c}\text { Iribarren } \\
\text { w. wave height } H_{0}\end{array}$ \\
\hline 3 days & -0.30 & 0.24 & -0.39 & 0.42 \\
\hline 5 days & -0.44 & 0.14 & -0.20 & 0.29 \\
\hline 7 days & -0.66 & -0.47 & 0.25 & 0.04 \\
\hline
\end{tabular}

\section{CONCLUDING REMARKS}

Multi-year time series of ARGUS derived beach states at Palm Beach, Sydney and Duck, NC and concurrent wave data were analysed to quantify the nearshore morphological recovery time scales $\left(T_{m r}\right)$ 
and determine the physical processes that may govern $T_{m r}$. The analysis shows that $T_{m r}$ is of the order of 5-10 days at these two beaches. While $T_{m r}$ at the single barred Palm beach (11 days) is double that of the double barred Duck beach (5 days), whether morphological recovery is indeed generally slower at single barred beaches relative to double barred beaches is a question that cannot be conclusively answered without investigating this phenomenon at several other sites.

$T_{m r}$ is moderately positively correlated with the averaged longshore current over the 3 days immediately after the resetting storm at Palm beach (longshore currents at Duck could not be estimated as wave direction information was not available). While this indicates that it might be possible to develop a predictor for $T_{m r}$ based on wave conditions immediately after the resetting storm, the general applicability of this correlation needs to be rigorously investigated at other sites.

The only other moderate correlations are seen between $T_{m r}$ and the wave heights during the latter part of the recovery process (last 7 days of the recovery duration). However, the positive and negative correlations between $T_{m r}$ and wave height at Palm beach and Duck (respectively) are confounding. As these correlations are with a property at the end of the recovery period, it is not possible to develop a useful predictor of $T_{m r}$ based on this observation.

Weak correlations are present between $T_{m r}$ and several pre-storm, during-storm and post-storm parameters at the two sites (e.g. antecedent beach state, maximum wave height during storm, storm power, Iribarren (3 day post storm average), longshore current (5 day post storm average at Palm). However, these correlations are intriguingly inconsistent between the two sites.

While this study has resulted in some first insights into nearshore morphological recovery time scales, it highlights the need for a thorough analysis employing long-term beach state and wave data at several different study sites to fully understand this phenomenon.

\section{ACKNOWLEDGMENTS}

R. Ranasinghe and M. Stive are partly supported by the European Research Council under the European Community's Seventh Framework Programme (FP7/2007-2013) / ERC Grant agreement ${ }^{\circ}$ [291206 ]-NEMO. MdeS was funded by the innovation program Building with Nature under project code NTW 3.2. The Building with Nature program is funded from several sources, including the Subsidieregeling Innovatieketen Water (SIW, Staatscourant nrs 953 and 17009) sponsored by the Dutch Ministry of Transport, Public Works and Water Management and partner contributions of the participants to the Foundation EcoShape. The program receives co-funding from the European Fund for Regional Development EFRO and the Municipality of Dordrecht.

\section{REFERENCES}

Battjes, J.A. 1974. Surf similarity, Proceedings of the International Conference on Coastal Engineering; No 14.

Brander, R.W. 1999 Field observations on the morphodynamic evolution of a low-energy rip current system. Marine Geology, 157 (3-4), pp. 199-217

Callaghan, D.P., Nielsen, P., Short, A., Ranasinghe, R., 2008. Statistical simulation of wave climate and extreme beach erosion. Coastal Engineering 55 (5), 375-390.

Calvete, D., G. Coco, A. Falqués, and N. Dodd .2007. (un)predictability in rip channel systems, Geophys. Res. Lett., 34 (5).

Castelle, B., V. Marieu, G. Coco, P. Bonneton, N. Bruneau, and B. G. Ruessink . 2012. On the impact of an offshore bathymetric anomaly on surf zone rip channels, J. Geophys. Res., 117.

Damgaard, J., N. Dodd, L. Hall, and T. Chesher. 2002. Morphodynamic modelling of rip channel growth, Coastal Engineering,., 45, 199- 221

Drønen, N., and R. Deigaard. 2007. Quasi-three-dimensional modelling of the morphology of longshore bars, Coastal Engineering, 54 (3).

Lippmannn, T. C. and R. Holman. 1990. The Spatial and Temporal Variability of Sand Bar Morphology. J. of Geophysical Research, 95: 11575-11590

Ojeda, E., J. Guillén, and F. Ribas. 2011. Dynamics of single barred embayed beaches, Marine Geology, 280 (14).

Price, T. D., and B. G. Ruessink. 2011. State dynamics of a double sandbar system, Continental Shelf Research, 31 (6). 
Ranasinghe, R. G. Symonds, K. Black and R. Holman. 2004. Morphodynamics of Intermediate Beaches: A Video Imaging and Numerical Modelling Study. Coastal Engineering, Vol. 51, 629655.

Ranasinghe, R. D. Callaghan and M. J. F. Stive. 2012. Estimating coastal recession due to sea level rise: Beyond the Bruun Rule. Climatic Change, Vol 110: 561-574

Reniers, A.., J. A. Roelvink, and E. B. Thornton. 2004. Morphodynamic modeling of an embayed beach under wave group forcing, J. Geophys. Res., 109.

Smit, M. W. J., A. J. H. M. Reniers, B. G. Ruessink, and J. A. Roelvink. 2008. The morphological response of a nearshore double sandbar system to constant wave forcing, Coastal Engineering, 55 (10).

Turner, I. L., D. Whyte, B. Ruessink, and R. Ranasinghe. 2007. Observations of rip spacing, persistence and mobility at a long, straight coastline, Marine Geology, 236 (3-4), 209-221,

Wright, L. D. and A. D. Short. 1984. Morphodynamic Variability of Surf Zones and Beaches. Marine Geology, 56: $93-118$.

Wright, L.D., Short, A.D. and Green, M.O., 1985. Short-term changes in the morphodynamic states of beaches and surf zones: An empirical predictive model. Marine Geology, 62: 339--364. 